\title{
BJPsych Open fifth anniversary editorial: history, accomplishments, trajectory and passion
}

Kenneth R. Kaufman

\section{Summary}

BJPsych Open has come of age. This editorial celebrates the journal's fifth anniversary by reviewing the history of BJPsych Open, what we have accomplished, where we strive to go (our planned trajectory) and the passion of being an Editor-in-Chief.

\section{Keywords}

BJPsych Open; academic publishing; history; anniversary; methodologic rigor; research ethics; publication integrity; metrics; thematic issues; global reach; editorial board; authors; reviewers; Plan S; passion of an Editor-in-Chief.

\section{Copyright and usage}

(c) The Author 2020. Published by Cambridge University Press on behalf of the Royal College of Psychiatrists. This is an Open Access article, distributed under the terms of the Creative Commons Attribution-NonCommercial-NoDerivatives licence (http://creativecommons.org/licenses/by-nc-nd/4.0/), which permits non-commercial re-use, distribution, and reproduction in any medium, provided the original work is unaltered and is properly cited. The written permission of Cambridge University Press must be obtained for commercial re-use or in order to create a derivative work
Kenneth R. Kaufman (pictured) is Editor-in-Chief of BJPsych Open and Professor of Psychiatry, Neurology and Anesthesiology at Rutgers Robert Wood Johnson Medical School, New Brunswick, New Jersey, USA. He is Visiting Professor of Psychological Medicine at the Institute of Psychiatry, Psychology \& Neuroscience, King's College London, UK

This year we celebrate the fifth anniversary of the first issue of BJPsych Open, a society journal for the Royal College of Psychiatrists (RCPsych). We do so in the midst of the coronavirus disease 2019 (COVID-19) pandemic, for it is important to celebrate these positive moments and what brings us together. As Editor-inChief, I am deeply passionate regarding this journal and the entire RCPsych portfolio. Knowledge is power: power to understand disease pathology and epidemiology, create meaningful diagnostic criteria with consistent terminology for research and clinical care, improve treatment with decreased morbidity and mortality, decrease nonadherence, improve quality of life with decreased stigma and barriers, direct national and international policy with appreciation of novel interventions and healthcare economics, and focus on research integrity and publication ethics. BJPsych Open strives to expand and disseminate knowledge through our community of authors, reviewers, editorial board members and editorial and production staff. As an academic clinician for the past 45 years, a key lesson learned and shared with my patients has been, and continues to be, the need to always reinvent oneself over time, and in BJPsych Open I have been reinvented and found both a professional and even personal home. Let me tell you the story of BJPsych Open: how we started, what we have accomplished and where we strive to go.

\section{History of BJPsych Open}

In 2014, at the RCPsych reception at the American Psychiatric Association in New York City, Professor Bhui addressed formative thoughts regarding an open-access journal for the RCPsych portfolio. His concerns mirrored thoughts from the College: not all meaningful research with methodologic rigor submitted to the British Journal of Psychiatry (BJPsych) could possibly be published because of print limitations. Two questions were posed. Although print journals such as BJPsych have a finite number of pages and articles that can be published annually, was shortage of print space precluding appropriate dissemination of methodologically sound knowledge to college members and the larger scientific audience consistent with long-term college academic goals? Did the College and the publication team have a solution, one that matched the changing landscape in academic publishing? The answers were straightforward - no, it was not consistent with long-term college academic goals, and yes, there was a proposed solution - leading to the gestation of BJPsych Open. Open access was chosen to maximise dissemination of knowledge, a core College principle, and the new face of academic publishing. With the changing trends in open science and publishing, it was felt that this new journal would become an important part of the RCPsych portfolio. BJPsych Open was seen initially as a cascade journal for those papers not accepted by BJPsych but that met appropriate quality standards, with the ultimate intention and expectation to have increasing independent submissions as the stature of the new journal grew. Only seven members comprised the founding editorial board: Professor Bhui, who was Editor of BJPsych and College Editor, serving as Editor-in-Chief for BJPsych Open, with Professor Malhi (Australia) and Professor Kaufman (USA) serving as Deputy Editors in addition to four Associate Editors (Amanda Baxter, Peter Byrne, Anne Lingford-Hughes and Peter Haddad). Call for papers resulted in first submissions in early 2015, with the first issue published in June 2015 (20 articles, including editorials, short reports, research articles and reviews, with 107 authors representing 11 countries) - a new, international open-access journal had been born. ${ }^{1}$

In 2016, volume two expanded to six issues. As noted in the editorial marking the first anniversary of the first BJPsych Open issue, 70 articles (483 pages) had been published in the first 5 issues. ${ }^{2}$ Consider the rapid expansion of submissions and international acceptance of the journal: 250 submissions from 1457 authors representing 38 countries during the first 18 month (the journal received submissions for 6 months before the first issue). ${ }^{2}$ 
During 2017, the College and Cambridge University Press (CUP) formed a publication partnership for the RCPsych-CUP portfolio and a transition in Editor-in-Chief occurred, with Professor Kaufman assuming that role. An editorial marking this transition noted that during the first 36 months, 2918 authors from 43 countries had submitted 489 articles. $^{3}$

Both 2018 and 2019 noted continued strength and further expansion of the journal. In 2018, 76 papers (513 pages) were published and in 2019, 95 papers (683 pages) were published. Further, the current Editor-in-Chief actively focused on increasing the editorial board membership, academic strengths, disciplines covered and international base. By the end of 2019, the founding 7member editorial board ( 5 men and 2 women) had been expanded to 38 (17 men and 21 women, representing 15 countries from 6 continents). Further, our reviewers, $>1000$ unsung heroes from $>50$ countries, have provided essential critical appraisals required for rigorous peer review.

\section{What we have accomplished}

Numerically, during the lifespan of BJPsych Open (through 31 March 2020), 900 original articles were submitted from $>6000$ total authors/coauthors (4062 individual authors/coauthors without duplications) representing over 53 countries from which 369 papers were accepted ( $>2500$ total authors/coauthors, with 1750 without duplication, representing 43 countries). As of 31 March 2020, 360 papers (1995 pages) have been published.

More importantly, there are numerous memorable articles that continue to be read and cited as well as guide clinicians, leading to further research and affecting policy. Altmetrics reveal increasing views, downloads and international discussion of BJPsych Open articles. Noteworthy publications include, but are not limited to, the following articles:

- Ethical considerations in placebo-controlled randomised clinical trials $^{4}$

- Clinical effectiveness of a skills training intervention for caregivers in improving patient and caregiver health following inpatient treatment for severe anorexia nervosa: pragmatic randomised controlled trial ${ }^{5}$

- Childhood IQ and risk of bipolar disorder in adulthood: prospective birth cohort study ${ }^{6}$

- High heterogeneity and low reliability in the diagnosis of major depression will impair the development of new drugs ${ }^{7}$

- Claims for sickness and disability benefits owing to mental disorders in the UK: trends from 1995 to $2014^{8}$

- Long-term antipsychotic treatment in schizophrenia: systematic review and network meta-analysis of randomised controlled trials $^{9}$

- Light therapy for non-seasonal depression: systematic review and meta-analysis $^{10}$

- Case finding and screening clinical utility of the Patient Health Questionnaire (PHQ-9 and PHQ-2) for depression in primary care: a diagnostic meta-analysis of 40 studies $^{11}$

- A systematic review and synthesis of outcome domains for use within forensic services for people with intellectual disabilities ${ }^{12}$

- Gestational vitamin D deficiency and autism spectrum disorder ${ }^{13}$

- Lamotrigine-induced sexual dysfunction and non-adherence: case analysis with literature review ${ }^{14}$

- Trends in female authorship in research papers on eating disorders: 20 -year bibliometric study ${ }^{15}$

- The prevalence and treatment outcomes of antineuronal antibody-positive patients admitted with first episode of psychosis ${ }^{16}$

- Mother and baby units matter: improved outcomes for both ${ }^{17}$
- Suicide attempts and non-suicidal self-harm: national prevalence study of young adults ${ }^{18}$

- Association between suicidal ideation and suicide: meta-analyses of odds ratios, sensitivity, specificity and positive predictive value $^{19}$

- Predicting major mental illness: ethical and practical considerations ${ }^{20}$

- Indirect costs of depression and other mental and behavioural disorders for Australia from 2015 to $2030^{21}$

- Social gradients in the receipt of medication for attention-deficit hyperactivity disorder in children and young people in Sheffield ${ }^{22}$ - Long-term subjective memory after electroconvulsive therapy ${ }^{23}$

The breadth of published articles ranges from treatment efficacy to adverse effects, from nonadherence to social gradients in prescriptions, from forensic psychiatry to mental health law, from ethics to global mental health, from history of terminology to guidelines, from digital mental health to determination of value and healthcare economics, from neuropsychiatry to perinatal psychiatry, from stigma to quality of life....and the list goes on.

Further, we published our first thematic series, the eight-paper Emerald Series ${ }^{24-31}$ under the leadership of Professor Sir Graham Thornicroft (BJPsych Open Associate Editor). As described in a prior editorial, ${ }^{3}$ annual thematic series are a vision for this journal, and several have been commissioned for the coming years.

A critical aspect of BJPsych Open and all journals within the RCPsych-CUP portfolio is the maintenance of research integrity and publication ethics. Issues are often raised in the Senior Editorial Committee (chaired by Professor Bhui with this author and other members of the BJPsych and BJPsych Open board). For BJPsych Open, senior-level review of a proposed corrigendum led to one retraction, ${ }^{32}$ and the later resubmission with reanalysis of data of this important paper was recently published. ${ }^{33}$ In light of issues that have arisen within the portfolio, ${ }^{32,34}$ a working group on integrity and ethics has been created, with planned publications in BJPsych, BJPsych Open and BJPsych Advances. The editorial office has instituted further checks to ensure maximal compliance with all ethical standards.

Efforts by the entire team to enhance the quality of this journal have been noticed. BJPsych Open is now abstracted/indexed in PubMed Central, Science Citation Index Expanded (SciSearch), Journal Citation Reports/Science Edition, Current Contents/ Clinical Medicine, PsycINFO, Directory of Open Access Journals (DOAJ) and Scopus. As we go to print, we are pending notification of our first Impact Factor for 2019.

With the existence of commissioned articles and discretionary waivers, it has been possible to encourage submissions and publish articles from a series of important authors and research groups regardless of the open-access fees.

\section{Where do we strive to go: our planned trajectory}

BJPsych Open focuses on being a high-quality journal, publishing methodologically rigorous research in psychiatry and disciplines related to mental health, and always strives to increase quality of submissions and published articles in the coming years. To this end, it has been important to develop the editorial board and reviewers, for they serve as judges of quality and relevance. We have been fortunate to have expanded both editorial board membership and reviewers during the lifetime of the journal, and this will continue to be a priority.

As BJPsych Open has matured, a gradual decrease in overlap between the BJPsych and BJPsych Open boards has naturally occurred, and from 1 April 2020 the BJPsych Open Editorial Board became totally independent from the BJPsych Editorial 
Board. This means that we not only have more resources to focus on BJPsych Open's development, but that BJPsych Open complies with various funder requirements, such as those outlined in Plan S (Plan $\mathrm{S}$ is the fundamental restructuring of scholarly publication focusing on maximal dissemination of knowledge through affordable open access from grant-funded research. For specific details, refer to Plan S Principles and Implementation at https://www.coali tion-s.org/addendum-to-the-coalition-s-guidance-on-the-implemen tation-of-plan-s/principles-and-implementation/.

As part of the separation of the two editorial boards, the BJPsych Open Editorial Board was restructured to increase the number of Deputy Editors (Regi Alexander, Richard Williams, Eva Petkova, Thomas Schulze, Allan Young and Marco Mula), who will have specific responsibilities, including jointly developing and overseeing thematic series.

A series of thematic series are being planned for this and coming years: Cognition in Mood Disorders, Caring for Healthcare Practitioners, Autism Spectrum Disorder in Low- and MiddleIncome Countries, Stigma in Mental Health, Treatment Adherence, Digital Mental Health, Nicotine and Psychiatry, Biomarkers in Psychiatry and Global Mental Health Initiatives, among others.

When considering the future for BJPsych Open during the Editor-in-Chief transition editorial, ${ }^{3}$ one area for research and publication was not addressed: advocacy. Advocacy is a key means to address the many barriers to treatment. It is hoped that in the coming years BJPsych Open will be an outlet to publish the effect of advocacy on patients, families, healthcare providers, healthcare systems and policy. A further area for research and publication was not then imagined: COVID-19. It is important that we publish both clinically and socially meaningful articles on the effect of threats such as COVID-19 on the mental health of the general population and those already with psychiatric disorders, as well as considering the effect on healthcare providers, health systems and policy. ${ }^{35}$ As outlined in the transition editorial, ${ }^{3}$ the vision for BJPsych Open remains unchanged, and if anything has been expanded.

BJPsych Open will continue to be a general psychiatric journal, but one that listens to our audience (clinicians, clinical academics, researchers and policy makers) as well as authors, reviewers and editorial board members concerning what should be done to further improve quality and breadth of the journal. Further, as a society journal (RCPsych), we adhere to all College policies and work with the College for the maximum dissemination of knowledge.

\section{The passion of being an Editor-in-Chief}

I introduced this editorial by referring to my being deeply passionate regarding this journal and the entire RCPsych portfolio. How could I not be passionate when given the rare opportunity to head a new journal in a prestigious portfolio? BJPsych Open does what I have always believed in: dissemination of knowledge with methodologically sound research, short reports, editorials, commentaries and special articles. Further, as an open-access journal with discretionary waivers, there is maximal democratisation of knowledge.

Although numbers are interesting and speak of the growing importance of BJPsych Open for clinicians, clinical academics, researchers and even policy makers, numbers tell only half of the tale. Why do I now view BJPsych Open as my professional and even personal home? In BJPsych Open (as well as BJPsych), I have kindred souls on the board as well as in fellow reviewers and authors - individuals who are both colleagues and friends. The board meetings held at the College are highlights in which we first speak as colleagues of journal policies, and then we speak as friends.

As Editor-in-Chief, I can focus on topics which I consider of clinical and policy import; I have the ability to commission articles on innovative interventions; I can work with our dedicated team on multiple thematic issues; I can think not simply of what will be accomplished this year, but what will be done during the next 5 years. I learn from the submitted articles, reviews, authors' responses and the editorial board. As a general psychiatric journal, BJPsych Open truly broadens my knowledge base - the articles we publish makes one think. Perhaps this is what all journals strive for the most: to make our readers think, and by doing so, become better clinicians and researchers.

None of what has been accomplished or what we strive to do in the coming years would be possible without a very dedicated team whose vision and efforts have made this journey possible. Many thanks to our international team of authors, reviewers, editorial board members (see https://www.cambridge.org/core/journals/ bjpsych-open/information/editorial-board; this link will update as the board further transitions), editorial staff (Anna Munks, Managing Editor) and production staff (CUP). All the efforts from this team are especially meaningful in the presence of COVID-19, with many of us now working from home, teaching online and having different but increased responsibilities and concerns.

When I awaken each morning in the USA (GMT minus $5 \mathrm{~h}$ ), I am eager to check my Editor-in-Chief and Handling Editor dashboards and read the emails from London that have already been sent regarding journal questions. Each day with BJPsych Open has both meaning and passion.

Kenneth R. Kaufman (D), MD, FRCPsych, DLFAPA, FAES, Departments of Psychiatry, Neurology and Anesthesiology, Rutgers Robert Wood Johnson Medical School, New Jersey, USA; and Department of Psychological Medicine, Institute of Psychiatry, Psychology \& Neuroscience, King's College London, UK

Correspondence: Kenneth R. Kaufman. Email: kaufmakr@rwjms.rutgers.edu

First received 1 Apr 2020, final revision 12 Apr 2020, accepted 16 Apr 2020

\section{Declaration of interest}

K.R.K. is Editor-in-Chief of BJPsych Open and member of the British Journal of Psychiatry International Editorial Board.

ICMJE forms are in the supplementary material, available online at https://doi.org/10.1192/ bjo.2020.34

\section{References}

1 Bhui K, Malhi GS, Kaufman KR. Open sesame: a new generation journal. BJPsych Open 2015; 1(1): e1-2.

2 Kaufman KR, Malhi GS, Baxter A, Bhui K. In an open publishing house not so far, far away... BJPsych Open 2016; 2(4): e12-3.

3 Kaufman KR. BJPsych Open editorial transition: opportunity, challenge, and vision. BJPSych Open 2018; 4(1): 29-30.

4 Kaufman KR. Ethical considerations in placebo-controlled randomised clinical trials. BJPsych Open 2015; 1(1): e3-4.

5 Hibbs R, Magill N, Goddard E, Rhind C, Raenker S, Macdonald P, et al. Clinical effectiveness of a skills training intervention for caregivers in improving patient and caregiver health following in-patient treatment for severe anorexia nervosa: pragmatic randomised controlled trial. BJPSych Open 2015; 1(1): 56-66.

6 Smith DJ, Anderson J, Zammit S, Meyer TD, Pell JP, Mackay D. Childhood IQ and risk of bipolar disorder in adulthood: prospective birth cohort study. BJPSych Open 2015; 1(1): 74-80.

7 Lieblich SM, Castle DJ, Pantelis C, Hopwood M, Young AH, Everall IP. High heterogeneity and low reliability in the diagnosis of major depression will impair the development of new drugs. BJPsych Open 2015; 1(2): e5-7. 
8 Viola S, Moncrieff J. Claims for sickness and disability benefits owing to mental disorders in the UK: trends from 1995 to 2014. BJPsych Open 2016; 2(1): 18-24.

9 Zhao YJ, Lin L, Teng M, Khoo AL, Soh LB, Furukawa TA, et al. Long-term antipsychotic treatment in schizophrenia: systematic review and network metaanalysis of randomised controlled trials. BJPsych Open 2016; 2(1): 59-66.

10 Perera S, Eisen R, Bhatt M, Bhatnagar N, de Souza R, Thabane L, et al. Light therapy for non-seasonal depression: systematic review and meta-analysis BJPsych Open 2016; 2(2): 116-26.

11 Mitchell AJ, Yadegarfar M, Gill J, Stubbs B. Case finding and screening clinical utility of the Patient Health Questionnaire (PHQ-9 and PHQ-2) for depression in primary care: a diagnostic meta-analysis of 40 studies. BJPsych Open 2016; 2(2): 127-38.

12 Morrissey C, Langdon PE, Geach N, Chester V, Ferriter M, Lindsay WR, et al. A systematic review and synthesis of outcome domains for use within forensic services for people with intellectual disabilities. BJPsych Open 2017; 3(1): 41-56.

13 Vinkhuyzen AAE, Eyles DW, Burne THJ, Blanken LME, Kruithof CJ, Verhulst F, et al. Gestational vitamin D deficiency and autism spectrum disorder. BJPsych Open 2017; 3(2): 85-90.

14 Kaufman KR, Coluccio M, Sivaraaman K, Campeas M. Lamotrigine-induced sexual dysfunction and non-adherence: case analysis with literature review. BJPsych Open 2017; 3(5): 249-53.

15 Strand M, Bulik CM. Trends in female authorship in research papers on eating disorders: 20-year bibliometric study. BJPsych Open 2018; 4(2): 39-46.

16 Scott JG, Gillis D, Ryan AE, Hargovan H, Gundarpi N, McKeon G, et al. The prevalence and treatment outcomes of antineuronal antibody-positive patients admitted with first episode of psychosis. BJPsych Open 2018; 4(2): 69-74.

17 Stephenson LA, Macdonald AJD, Seneviratne G, Waites F, Pawlby S. Mother and baby units matter: improved outcomes for both. BJPsych Open 2018; 4(3): 119-25.

18 O'Connor RC, Wetherall K, Cleare S, Eschle S, Drummond J, Ferguson E, et al. Suicide attempts and non-suicidal self-harm: national prevalence study of young adults. BJPsych Open 2018; 4(3): 142-8.

19 McHugh CM, Corderoy A, Ryan CJ, Hickie IB, Large MM. Association between suicidal ideation and suicide: meta-analyses of odds ratios, sensitivity, specificity and positive predictive value. BJPsych Open 2019; 5(2): e18

20 Lawrie SM, Fletcher-Watson S, Whalley HC, McIntosh AM. Predicting major mental illness: ethical and practical considerations. BJPSych Open 2019; 5(2): e30.

21 Schofield D, Cunich M, Shrestha R, Tanton R, Veerman L, Kelly S, et al. Indirect costs of depression and other mental and behavioural disorders for Australia from 2015 to 2030. BJPsych Open 2019; 5(3): e40.

22 Nunn SPT, Kritsotakis El, Harpin V, Parker J. Social gradients in the receipt of medication for attention-deficit hyperactivity disorder in children and young people in Sheffield. BJPsych Open 2020; 6(2): e14.

23 Sigström R, Nordenskjöld A, Jureus A, Clements C, Joas E, Pålsson E, et al. Longterm subjective memory after electroconvulsive therapy. BJPSych Open 2020; 6(2): e26.
24 Thornicroft G, Semrau M. Health system strengthening for mental health in lowand middle-income countries: introduction to the Emerald programme. BJPsych Open 2019; 5(5): e66.

25 Evans-Lacko S, Hanlon C, Alem A, Ayuso-Mateos JL, Chisholm D, Gureje O, et al. Evaluation of capacity-building strategies for mental health system strengthening in low- and middle-income countries for service users and caregivers, policymakers and planners, and researchers. BJPsych Open 2019; 5(5): e67.

26 Chisholm D, Docrat S, Abdulmalik J, Alem A, Gureje O, Gurung D, et al. Mental health financing challenges, opportunities and strategies in low- and middleincome countries: findings from the Emerald project. BJPsych Open 2019; 5 (5): e68

27 Petersen I, van Rensburg A, Kigozi F, Semrau M, Hanlon C, Abdulmalik J, et al. Scaling up integrated primary mental health in six low- and middle-income countries: obstacles, synergies and implications for systems reform. BJPsych Open 2019; 5(5): e69.

28 Jordans M, Chisholm D, Semrau M, Gurung D, Abdulmalik J, Ahuja S, et al. Evaluation of performance and perceived utility of mental healthcare indicators in routine health information systems in five low- and middle-income countries. BJPsych Open 2019; 5(5): e70.

29 Ahuja S, Hanlon C, Chisholm D, Semrau M, Gurung D, Abdulmalik J, et al. Experience of implementing new mental health indicators within information systems in six low- and middle-income countries. BJPSych Open 2019; 5(5): e71.

30 Ayuso-Mateos JL, Miret M, Lopez-Garcia P, Alem A, Chisholm D, Gureje O, et al. Effective methods for knowledge transfer to strengthen mental health systems in low- and middle-income countries. BJPsych Open 2019; 5(5): e72.

31 Semrau M, Alem A, Ayuso-Mateos JL, Chisholm D, Gureje O, Hanlon C, et al. Strengthening mental health systems in low- and middle-income countries: recommendations from the Emerald programme. BJPsych Open 2019; 5(5): e73.

32 Kaufman KR, Malhi GS, Bhui KS. When a corrigendum is not sufficient. BJPsych Open 2019; 5(4): e55.

33 Davis KAS, Coleman JRI, Adams M, Allen N, Breen G, Cullen B, et al. Mental health in UK Biobank - development, implementation and results from an online questionnaire completed by 157366 participants: a reanalysis. BJPsych Open 2020; 6(2): e18.

34 Bhui KS, Lee W, Kaufman KR, Lawrie SM. Ensuring research integrity: setting standards for robust and ethical conduct and reporting of research. $\mathrm{Br} J$ Psychiatry 2019; 215(1): 381-2.

35 Kaufman KR, Petkova E, Bhui KS, Schulze TG. A global needs assessment in times of a global crisis: world psychiatry response to the COVID-19 pandemic. BJPsych Open [Epub ahead of print] 6 Apr 2020. Available from: https://doi.org/ 10.1192/bjo.2020.25. 